\title{
Clinical and Dermoscopic Features of Lichen Amyloidosis : A Case Report
}

\author{
El Anzi Ouiam*, Maouni Safae, Sqalli Asmae and Hassam Badredine \\ Department of Dermatology-Venereology, Morocco \\ *Corresponding author: El Anzi Ouiam, Department of Dermatology-Venereology, Morocco
}

\begin{abstract}
Lichen amyloidosis (LA) is the most common form of primary cutaneous amyloidosis. It's a very pruritic hyperkeratotic and coalescent papules usually localized on the anterior tibiae. The diagnostic is clinical, dermoscopy reveals two major dermoscopic patterns characteristic of LA, namely, 'central hub' and 'scar-like'.
\end{abstract}

Keywords: Lichen amyloidosis; Dermoscopy; Pruritus; Papules

\section{Introduction}

Papular amyloidosis, formerly called lichen amyloidosis (LA) is the most common form of primary cutaneous amyloidosis, histologically characterized by accumulation amyloid deposits in the dermis. It's a very pruritic hyperkeratotic and coalescent papules usually localized on the anterior tibiae. We reported the case of a 70 year old man with 2 years history of a pruritic papular eruption on the lower legs (Figure 1).

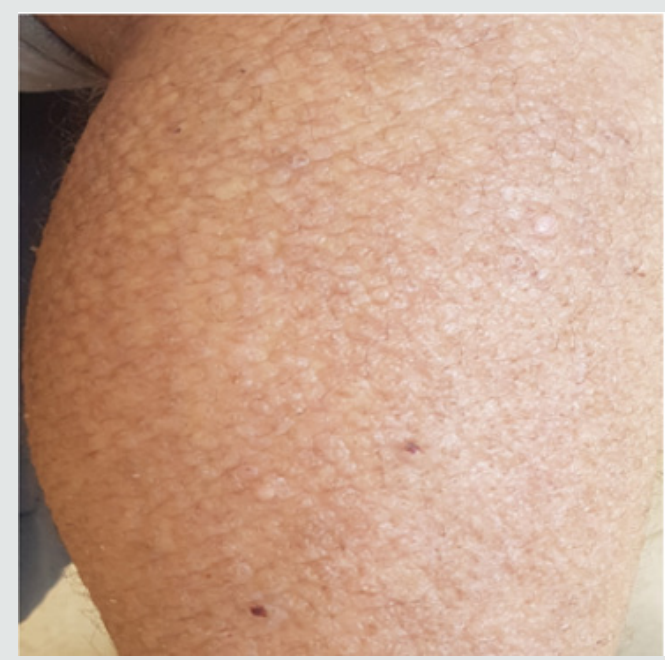

Figure 1: The clinical picture of a patient with lichen amyloidosus on the lower limb.

\section{Clinical case}

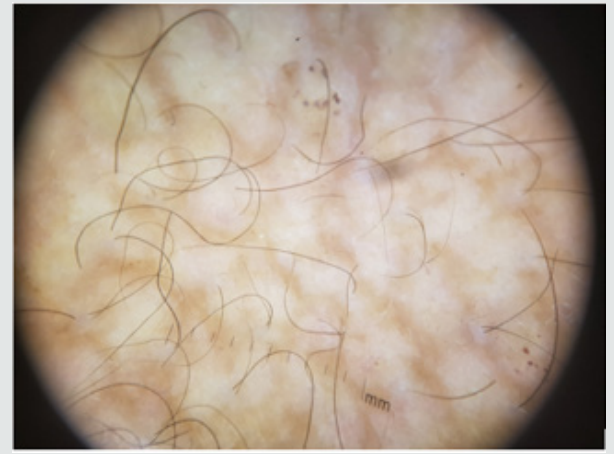

Figure 2A: Dermoscopic examination showing scar-like structureless area.

An 80 years old woman with antecedents of high blood pressure and diabetes has consulted for pruriginous lesions of the anterior surfaces of the legs and knees evolving since 2 years. The clinical examination revealed multiple yellowish papules firm and rough on palpation on the lower limbs. The diagnosis of LA has been made and was confirmed by cutaneous biopsy with compact orthohyperkeratosis, acanthosis and amorphous amyloid deposits in the dermal papillae (Figure 2A). Dermoscopic examination showed a whitish scar-like center with structureless morphology surrounded by some brownish dots which is very specific to LA. 


\section{Comments}

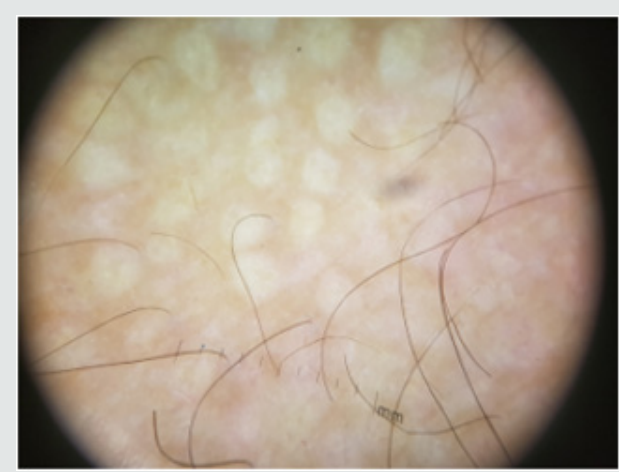

Figure 2B: Dermoscopic examination showing scar-like structureless area.

Lichen amyloidosis is the most frequent type of primary localized cutaneous amyloidosis [1]. It is clinically characterized by pruritic keratotic distributed frequently on the anterior tibiae and occasionally on the trunk and upper extremities [1-2]. The differential diagnosis is made with mucinosis, lichen simplex chronicus and prurigo nodularis [1-3]. The diagnosis is clinical (Figure 2B). A skin biopsy should be reserved for evolving lesions. Chuang et al. [1] described two major dermoscopic patterns characteristic of LA, namely, 'central hub' and 'scar-like'. Two subtypes of 'scar-like' pattern were noticed, including one resembling a volcanic crater and the other displaying completely structureless morphology as we found in our patient [1-4].

\section{Conclusion}

Even if the diagnoses of LA is most often clinical, it can now be reinforced by dermoscopy.

\section{References}

1. YY Chuang, Lee DD, Lin CS, Chang YJ, Tanaka M, etal. (2012) Characteristic dermoscopic features of primary cutaneous amyloidosis: A study of 35 cases. Br J Dermato 167(3): 548-554.

2. Stephanie J Arnold, Jonathan CR Bowling (2012) Shiny white streaks in lichen amyloidosis: A clue to diagnosis. Australas J Dermato 53(4): 272273.

3. T Becha, $\mathrm{N}$ Litaiem, M Jones, A Raboudi, S Rammeh, et al. (2018) Amylose papuleuse : Aspect clinique et dermoscopique. Annales de Dermatologie et de Vénéréologie 145(4): 39.

4. S Idoudi, M Jones, N Litaiem, H Drissi, N Ezzine, et al. (2018) Amylose papuleuse : Une série de 7 cas illustrant deux hypothèses Physiopathologiques. Annales de Dermatologie et de Vénéréologie 145(4): 55.

\section{(C) This work is licensed under Creative}

To Submit Your Article Click Here: 